Original article

\title{
Impact of seasonal fluctuations in natural light on cerebral metabolism in Arctic region residents with different autonomic tones
}

\author{
Anatoly V. Gribanov ${ }^{1}$, Olga N. Kottsova ${ }^{1}$, Natalya Yu. Anikina ${ }^{2}$, Mikhail N. Pankov ${ }^{2}$, Larisa F. Startseva ${ }^{3}$ \\ ${ }^{1}$ Northern (Arctic) Federal University, Arkhangelsk, Russia \\ 2 Northern State Medical University, Arkhangelsk, Russia \\ ${ }^{3}$ State Institute of Medicines and Good Practices, Moscow, Russia
}

Received 4 February 2021, Revised 1 August 2021, Accepted 1 November 2021

(C) 2021, Russian Open Medical Journal

\begin{abstract}
Background - The study of physiological mechanisms of human acclimatization to extreme climatic conditions is an urgent task in current socioeconomic conditions of the Arctic region development. Natural cycles of seasonal adaptation based on light stimulus cause functional restructuring of the cerebral cortex and subcortical activity centers and change the activity of the autonomic nervous system.

Objective - The article aims at determining the characteristics of brain energy metabolism in Arctic region residents with different autonomic tones during different seasons.

Material and Methods - The first stage of our study was conducted using the computer appliance VNS-Spectrum (Neurosoft LLC, Russia) and resulted in setting up two groups: with predominance of the parasympathetic autonomic nervous system (26 subjects) and with prevailing sympathetic autonomic nervous system ( 23 individuals). At the second stage, the study of the seasonal dynamics in cerebral energy processes took place (in October, December, March, and June) by means of using the five-channel diagnostic complex Neuro-KM for topographic mapping of brain electrical activity via direct current potential levels (DCPL).

Results - Our results did not exhibit statistically significant gender-related differences, hence they permitted to form a single group. The results were compared with the software reference values for the norm.

Conclusion - Enlarged levels of natural light prompt the activation of energy metabolism in frontal and occipital lobes of the Arctic residents' cortex, accompanied by forming an exhaustion area in the temporal lobes. In the group of sympathotonic individuals, we revealed somewhat tense adaptation processes. Adaptation process of brain energy supply in vagotonic individuals occur less stressfully during the annual cycle.
\end{abstract}

Keywords: Arctic, photoperiodism, working age population, DC potential level, autonomic tone.

Cite as Gribanov AV, Kottsova ON, Anikina NYu, Pankov MN, Startseva LF. Impact of seasonal fluctuations in natural light on cerebral metabolism in Arctic region residents with different autonomic tones. Russian Open Medical Journal 2021; 10: e0426.

Correspondence to Olga N. Kottsova. Address: Department of Human Biology and Biotechnical Systems, Northern (Arctic) Federal University, 17 Naberezhnaya Severnoy Dviny, Arkhangelsk 163000, Russia. Phone: +79532677007. E-mail: olgank29@mail.ru.

\section{Introduction}

The functional biorhythms of the body are critical to human health. Many organ systems are under circadian control, including hormone secretion, cellular functions, gene expression, and regulation of sleep and wakefulness [1]. Some studies demonstrated that circadian disorders alter the function of brain regions involved in regulating emotions and mood $[2,3]$. The climate of northern regions is characterized by a short summer and a long fall-and-winter period with low temperatures, pronounced fluctuations in natural electromagnetic fields, and instability of atmospheric processes. Sometimes, changes in the light regime play an exclusive role among climatic factors. In Arkhangelsk, in November through February, people see little sunshine. As a result, there is a reduction in ultraviolet intensity virtually leading to biological polar night. The annual duration of sunshine in Arkhangelsk is on average 1,639 hours. During the year, the most significant sunshine is observed in July (334 hours), whereas the least sunshine is characteristic for December (1 hour).

Under constant exposure to extreme climatic factors, accurate body functioning is achieved through certain changes in nearly all life support systems via neurohumoral regulation [4-6]. The central nervous system controls the activity of the autonomic nervous system. It is regulated by subcortical nodes and the cerebral cortex [7-9]. The pronounced seasonal heterogeneity of natural light at northern latitudes can lead to changes in the tone of autonomic nervous system, along with excitement or inhibition of the central nervous system [10]. The bioelectric activity of brain was recorded to assess the central nervous system response [8]. In recent decades, the techniques based on analyzing the intensity of cerebral energy processes were actively employed [11, 12].

The sympathetic and parasympathetic divisions of the autonomic nervous system, as well as humoral influences, ensure 
achieving the optimal results in adapting to changing conditions of both external and internal environment. Optimal adaptive responses of a human body to external stimuli of the sensory organs are those, which require minimum health resources.

Acclimatization to the conditions of the Arctic region is achieved primarily by restructuring energy metabolism in the body. The human body moves to an energy efficient regulatory level. Compensatory adaptive responses of the central nervous system as a result of changes in the natural light level led to significant changes in cerebral energy processes [13]. Adaptive restructuring, requiring enhanced functioning of various brain structures, cause the formation of a specific energy state that could be described as an adaptive excess of cerebral energy exchange [14].

The dynamics of changes in cerebral metabolism of people with different autonomic tone types during the annual cycle is of particular interest, because it would allow determining the mechanisms of adaptation, versatility, and regulatory reserves of the body at varying natural light levels. That is why we were determined to conduct our study.

\section{Material and Methods}

\section{Subjects}

Study subjects were 63 young people of working age (30-34 years old) who were born and lived in the Arctic region.

\section{Research procedures}

The first stage of the study involved registering heart rate variability in order to determine the initial autonomic tone. The first stage results allowed us forming two groups: 26 subjects with vagotonia and 23 individuals with sympathicotonia. To avoid disadvantages of a small sample size, we excluded 14 normotonic subjects with a balanced type of heart rate regulation from further participation in the study.

The second stage of our study included investigating the seasonal dynamics of cerebral energy exchange via registering the levels of direct current potentials (DCPL), which represent one of the types of brain infra-low electrical activity. Due to availability of specific methods of analysis and topographic mapping, this equipment could be used to evaluate energy exchange in individual lobes of cerebral cortex and general indicators of cerebral metabolism [11]. An average monthly daytime duration during the research period (according to http://meteo.infospace.ru) was 9 hours 59 minutes in October, 4 hours 23 minutes in December, 12 hours in March, and 20 hours 57 minutes in June.

The third stage of the study encompassed processing and analyzing the results, followed by their interpretation.

\section{Measurements}

Heart rate variability (HRV) was recorded using the computer appliance VNS-Spectrum (Neurosoft LLC, Russia). When analyzing HRV, a set of the following indicators was considered: root-meansquare deviation (RMSD); root mean square of successive differences between normal heartbeats (RMSSD) as an indicator of the parasympathetic link activity of autonomic regulation; index of tension of regulatory systems (IN); power spectrum in the highfrequency range $(0.4-0.15 \mathrm{~Hz}), \mathrm{HF} \%$; power spectrum in the low- frequency range $(0.04$ to $0.15 \mathrm{~Hz})$, LF\%; power spectrum in the very-low-frequency range $(0.04-0.015 \mathrm{~Hz}), \mathrm{VLF} \%$; total power of HRV spectrum (TR, ms2) representing the total level of activity of regulatory systems; sympathetic-parasympathetic index - LF/HF, reflecting the balance of sympathetic and parasympathetic activity.

In the course of HRV analysis, the group of normotonic subjects was characterized by RMSD values of $40-80 \mathrm{~ms}$; RMSSD of 20-50 ms; IN of 80-150 conventional units; HF of 15-25\%; LF of $15-$ $40 \%$; VLF of $15-30 \%$; LF/HF of $1.5-2.0$ [15]. When the standard values of RMSD, RMSSD and HF\% were exceeded; and IN and $\mathrm{LF} / \mathrm{HF}$ values decreased, the subjects were assigned to the group of vagotonic individuals. With reduction in the standard values of RMSD, RMSSD and HF\%, accompanied by an increase in LF\%, VLF\%, IN and LF/HF, the subjects were assigned to the group of sympathotonic individuals.

Registration and analysis of DCPL were carried out using fivechannel computer appliance - diagnostic complex Neuro-KM (ASTEK, Russia). The study was conducted at the same time of the day, with the maximum physical and mental rest of the subjects. The potentials were recorded monopolarly in 5 leads using silver chloride electrodes EE-G2 and reference electrode EVL-1-M4. Prior to placing the electrodes, we carried out a preliminary test in saline, in the course of which the potential and resistance differences between the electrodes were measured in the absence of a biological object. The former did not exceed $20 \mathrm{mV}$, whereas the latter was $15-20 \mathrm{k} \Omega$; the drift of electrode potential did not exceed $1-2 \mathrm{mV}$ in $10 \mathrm{~min}$.

Active electrodes were positioned along the sagittal line of the frontal, central and occipital lobes ( $\mathrm{Fz}, \mathrm{Cz}, \mathrm{Oz})$, as well as in the right and left temporal lobes ( $\mathrm{Td}, \mathrm{Ts}$ ) sensu international standard 10-20 scheme. The reference electrode was placed on the left wrist. The electrodes were placed on the signal reading points with contact tampons moistened with hypertonic $(30 \%) \mathrm{NaCl}$ solution, due to which skin resistance declined to $1-2 \mathrm{k} \Omega$, skin potentials decreased, and galvanic skin reaction was blocked. DCPL were recorded 5-6 minutes after attaching the electrodes, and continuously through the entire study. During the experimental measurement, the duration of which was $15 \mathrm{~min}$, the values of skin resistance (which did not exceed $30 \mathrm{k} \Omega$ ) were monitored continuously at the same places, where DCPL were measured.

\section{Ethical approval}

All research manipulations were pursued with the permission issued by the Ethical Committee at the Institute of Biomedical Research, Northern (Arctic) Federal University (Protocol No.1 of January 1 , 2019). All procedures performed in studies involving human participants complied with the ethical standards of the institutional and/or national research committee and with 1964 Declaration of Helsinki and its later amendments, or comparable ethical standards.

\section{Data processing}

The analysis of DCPL distribution was carried out when mapping the monopolar values of DCP and calculating interelectrode differences. To assess the local DC values in each lobe, excluding the influence of the reference electrode, the DC deviations from the average for all cerebral cortex lobes were calculated, as well as the interhemispheric gradient (Td-Ts). The 
obtained data of DCPL distribution was then compared with the average standard values of the diagnostic complex.

Statistical processing of collected data was conducted using IBM SPSS Statistics 26 software package. One-dimensional descriptive statistics were calculated for each indicator, and the distributions of features were tested for normality. The results of nonparametric data processing were presented as a median and an interquartile range: $\mathrm{Me}(\mathrm{Q} 1 ; \mathrm{Q} 3)$. For intergroup comparison, Mann-Whitney $\mathrm{U}$ test was employed. Intragroup comparisons were carried out using the Wilcoxon signed-rank $T$ test. The differences were considered statistically significant at $p<0.05$.

\section{Results}

Comparative analysis of DCPL has revealed some peculiarity of energy consumption in the cerebral cortex of the Arctic region residents during different seasons depending on their autonomic tone. DCP values in the frontal lead $(\mathrm{Fz})$ in both study groups gradually increased throughout the study period from fall to summer, reaching the highest values in the summer period (Table 1).

The local indicator $\mathrm{Fz}-\mathrm{X}$, characterizing energy exchange processes of the frontal lobe relative to the average value of energy consumption in the cortex, had negative values in both vagotonic and sympathotonic subjects in seasons of reduced daylight time (fall and winter) and positive values with increasing daylight hours (spring and summer).

The DCPL in the central lead $(C z)$ had different annual dynamics in the studied groups. E.g., among vagotonic individuals, the highest DCP value was observed in winter, followed by a gradual decline throughout the year, reaching the minimum value in the fall. In sympathotonic individuals, during the period of decreasing natural light in fall and winter, the DCP value in the central lead was the highest. In spring, with an increased intensity of solar radiation, a drop in the potential in this lead was recorded, followed by its growth in summer.
Statistically significant differences between sympathotonic and vagotonic individuals were noted in DCPL seasonal fluctuations in the occipital lead $(\mathrm{Oz})$. The highest values of this potential in both study groups were recorded in the spring with an increased intensity of natural light. However, in sympathotonic subjects, the lowest annual DCPL was observed in winter, accompanied by an almost complete absence of insolation. Simultaneously, the DCP value was two times smaller than the corresponding indicator for vagotonic individuals during the same period. In the spring-andsummer period, we observed an almost double increase in the energy consumption registered in occipital lobe of sympathotonic individuals. In vagotonic individuals, DCPL in the occipital lead did not have sharp fluctuations throughout the year. In the fall, during the decrease in the intensity of sunshine, the minimum potential value was detected. With arrival of the 'biological polar night', there was a significant positive shift with further achievement of the maximum value in spring.

The annual dynamics of changes in DCP values in temporal leads ( $T d, T s)$ did not differ in sympathotonic vs. vagotonic individuals. The highest energy activity of the temporal lobes in both study groups was recorded in winter. In summer, with maximum exposure to natural light, the DCP values were becoming negative. The most significant reduction of the DCP value characterized left temporal signal reading point. During offseason periods (fall and spring), DCPL in vagotonic individuals approached the normal values for the residents of Central Russia, as was set in the software. At the same time, in this group, the most significant drop in the DCPL (about $20 \mathrm{mV}$ ) was noted in the winter-through-summer period. In sympathotonic individuals, the fall potential values for the temporal lobes were also within the normal range. However, in spring, there was a sharp drop in the level of potential due to the negative values of the left temporal lobe. In general, the range of DCP values in temporal lobes was about $14 \mathrm{mV}$, which was significantly lower than the corresponding indicator for vagotonic subjects.

Table 1. Monopolar, average and local values of DCPL distribution in Arctic residents with different autonomic tones (by seasons); Me (Q1; Q3), mV

\begin{tabular}{|c|c|c|c|c|c|}
\hline Lead & Autonomic tone & Fall & Winter & Spring & Summer \\
\hline \multirow{2}{*}{$\mathrm{Fz}$} & sympathotonic individuals & $7.3(1.4 ; 21.1)$ & $10.3(3.1 ; 20.1)$ & $14.0(7.6 ; 28.7)$ & $20.6(12.2 ; 25.3)$ \\
\hline & vagotonic individuals & *8.1 (1.4; 17.7) & $11.3(5.0 ; 21.1)$ & $16.9(7.9 ; 22.9)$ & $19.4(15.5 ; 25.4)$ \\
\hline \multirow{2}{*}{$\mathrm{Cz}$} & sympathotonic individuals & $17.2(6.7 ; 21.9)$ & $17.4(5.9 ; 25.7)$ & $14.3(7.4 ; 30.5)$ & $15.5(7.1 ; 28.0)$ \\
\hline & vagotonic individuals & $13.7(0.5 ; 23.1)$ & $* 22.9(15.0 ; 29.8)$ & $20.9(12.3 ; 33.4)$ & $19.4(9.5 ; 30.3)$ \\
\hline \multirow{2}{*}{$\mathrm{Oz}$} & sympathotonic individuals & $10.9(4.5 ; 13.7)$ & $7.1(4.7 ; 15.3)$ & *14.5 (11.0; 19.1) & $14.0(-1.0 ; 25.1)$ \\
\hline & vagotonic individuals & $11.5(7.0 ; 18.8)$ & $16.3(9.0 ; 26.5)^{*}$ & $17.1(10.5 ; 34.1)$ & $* 13.8(5.1 ; 21.0)$ \\
\hline \multirow{2}{*}{$\mathrm{Td}$} & sympathotonic individuals & *5.4 $(2.9 ; 13.5)$ & $11.7(4.3 ; 23.7)$ & *1.2 (-20.1; 9.2) & $-2.7(-26.6 ; 11.1)$ \\
\hline & vagotonic individuals & $* 6.0(-1.3 ; 10.6)$ & $* 15.2(6.2 ; 23.1)$ & $6.1(-1.7 ; 15.6)$ & $*-6.1(-25.4 ; 9.7)$ \\
\hline \multirow{2}{*}{ Ts } & sympathotonic individuals & *5.1 (-0.9; 13.0) & $9.9(2.9 ; 20.8)$ & ${ }^{*}-1.4(-18.0 ; 11.3)$ & $-4.3(-25.7 ; 14.6)$ \\
\hline & vagotonic individuals & $* 4.5(-4.0 ; 11.8)$ & $* 12.8(2.6 ; 18.9)$ & $8.0(-5.8 ; 18.1)$ & $*-12.2(-26.6 ; 7.5)$ \\
\hline \multirow{2}{*}{ Xcp } & sympathotonic individuals & $9.6(5.9 ; 15.5)$ & $12.3(5.2 ; 19.9)$ & $9.9(-0.9 ; 17.6)$ & $4.9(-4.2 ; 18.7)$ \\
\hline & vagotonic individuals & $6.8(5.0 ; 12.1)$ & *16.5 (7.7; 22.6) & $13.3(6.7 ; 23.3)$ & $* 2.8(-4.6 ; 16.0)$ \\
\hline \multirow{2}{*}{$\mathrm{Fz}-\mathrm{X}$} & sympathotonic individuals & ${ }^{*}-0.6(-5.9 ; 4.8)$ & $-2.6(-6.1 ; 6.0)$ & $* 5.9(4.8 ; 13.2)$ & $11.1(4.5 ; 18.7)$ \\
\hline & vagotonic individuals & $*-1.4(-5.5 ; 6.4)$ & $-2.2(-6.6 ; 2.2)$ & *2.2(-1.4; 5.5)* & $* 15.7(2.5 ; 23.0)$ \\
\hline \multirow{2}{*}{$\mathrm{Cz}-\mathrm{X}$} & sympathotonic individuals & $* 4.5(-1.1 ; 11.4)$ & $0.9(-1.9 ; 8.1)$ & *11.9 $(2.5 ; 18.8)$ & $9.8(8.3 ; 14.6)$ \\
\hline & vagotonic individuals & $* 6.7(-2.6 ; 12.2)$ & $5.1(2.3 ; 9.7)$ & $7.7(-0.3 ; 14.2)$ & $11.6(7.4 ; 17.7)$ \\
\hline \multirow{2}{*}{$\mathrm{Oz}-\mathrm{X}$} & sympathotonic individuals & $*_{-} 0.3(-4.2 ; 3.7)$ & $-3.4(-5.6 ; 0.9)$ & *6.9 $(2.1 ; 15.3)$ & $6.0(1.2 ; 10.5)$ \\
\hline & vagotonic individuals & $3.1(-0.3 ; 9.1)^{*}$ & $*-0.3(-2.6 ; 3.2)^{*}$ & $* 4.0(0.4 ; 13.2)$ & $3.9(-0.1 ; 10.5)$ \\
\hline \multirow{2}{*}{$T d-X$} & sympathotonic individuals & *-1.6 (-7.1; 1.9) & $1.1(-4.7 ; 3.4)$ & ${ }^{*}-13.1(-20.5 ;-3.8)$ & $-12.6(-20.9 ;-7.4)$ \\
\hline & vagotonic individuals & $*-3.0(-7.5 ; 0.8)$ & $0.05(-5.2 ; 3.1)$ & $*-6.0(-14.5 ;-2.1)$ & $-11.6(-22.3 ;-5.4)$ \\
\hline \multirow{2}{*}{ Ts-X } & sympathotonic individuals & ${ }^{*}-3.9(-8.8 ; 2.3)$ & $-0.1(-5.3 ; 6.7)$ & $*_{-11.0}(-20.0 ;-1.6)$ & $-12.8(-21.4 ;-8.4)$ \\
\hline & vagotonic individuals & $*_{-6.2}(-10.7 ; 1.1)$ & $-3.3(-7.5 ;-0.2)$ & $-7.1(-16.4 ; 0.4)$ & $-17.3(-22.0 ;-7.5)$ \\
\hline
\end{tabular}

* on the left - statistically significant differences between seasonal values within one group; ${ }^{*}$ on the right - statistically significant differences between the values of the same season for different groups. 
Table 2. Distribution of interelectrode DCPL values in Arctic residents, 30-34 years of age, with different autonomic tones; Me (Q1; Q3), $\mathrm{mV}$

\begin{tabular}{|c|c|c|c|c|c|}
\hline Lead & Autonomic tone & Fall & Winter & Spring & Summer \\
\hline \multirow{2}{*}{$\mathrm{Fz}-\mathrm{Cz}$} & sympathotonic individuals & $-4.0(-16.7 ; 0.1)$ & $-0.9(-13.9 ; 2.2)$ & $-3.8(-10.4 ; 5.3)$ & $1.6(-6.8 ; 10.6)$ \\
\hline & vagotonic individuals & $-7.3(-17.1 ; 10.1)$ & $-9.3(-17.3 ;-1.1)$ & $-5.4(-13.5 ; 1.0)$ & $0.7(-10.8 ; 13.0)$ \\
\hline $\mathrm{Fz}-\mathrm{Oz}$ & sympathotonic individuals & $-3.6(-8.4 ; 7.8)$ & $1.7(-3.8 ; 9.6)$ & $2.5(-5.6 ; 5.9)$ & $6.8(-5.0 ; 19.2)$ \\
\hline \multirow{2}{*}{ Fz-Td } & sympathotonic individuals & $* 0.2(-5.3 ; 13.2)$ & $0.6(-10.7 ; 5.9)$ & $* 25.0(5.4 ; 32.8)$ & $21.8(12.8 ; 39.4)$ \\
\hline & vagotonic individuals & $* 2.5(-5.6 ; 11.1)$ & $-4.2(-7.3 ; 4.8)$ & *7.7 $(2.8 ; 16.7)^{*}$ & *27.5 (13.6; 42.0) \\
\hline Fz-Ts & sympathotonic individuals & $* 1.3(-8.3 ; 11.8)$ & $-2.9(-12.8 ; 12.6)$ & *17.6 $(3.5 ; 32.4)$ & $25.1(8.3 ; 37.9)$ \\
\hline \multirow{2}{*}{$\mathrm{Cz}-\mathrm{Oz}$} & sympathotonic individuals & $4.6(-3.1 ; 12.8)$ & $2.1(-2.5 ; 15.1)$ & $3.1(-5.3 ; 8.5)$ & $3.9(-2.0 ; 11.2)$ \\
\hline & vagotonic individuals & $* 1.7(-6.1 ; 8.8)$ & *5.8 $(1.8 ; 10.7)$ & $*-1.1(-6.0 ; 8.8)$ & *6.3 $(2.4 ; 13.1)$ \\
\hline \multirow{2}{*}{$C z-T d$} & sympathotonic individuals & $* 7.4(-1.9 ; 16.6)$ & $2.3(-5.6 ; 12.1)$ & $* 19.2(6.3 ; 38.8)$ & $23.4(12.9 ; 34.5)$ \\
\hline & vagotonic individuals & *8.0 (0.6; 16.6) & $7.6(0.7 ; 12.0)$ & $* 12.6(7.0 ; 28.2)$ & *24.1(15.0; 35.6) \\
\hline \multirow{2}{*}{ Cz-Ts } & sympathotonic individuals & $* 9.1(-5.3 ; 18.4)$ & $3.2(-5.8 ; 12.6)$ & $* 21.4(3.6 ; 33.3)$ & $26.2(17.7 ; 32.2)$ \\
\hline & vagotonic individuals & $* 12.0(0.6 ; 24.5)$ & $10.3(2.2 ; 17.5)^{*}$ & $15.7(0.9 ; 28.8)$ & *28.0 (17.4; 36.6) \\
\hline \multirow{2}{*}{ Oz-Td } & sympathotonic individuals & $* 1.1(-2.6 ; 8.5)$ & ${ }^{*}-1.7(-7.3 ; 1.7)$ & $* 21.6(6.2 ; 35.4)$ & $20.5(10.1 ; 29.3)$ \\
\hline & vagotonic individuals & *7.9 (-0.2; 14.0) & $* 1.7(-5.3 ; 5.8)$ & *8.9 $(0.1 ; 28.3)$ & $16.0(5.1 ; 34.1)$ \\
\hline Oz-Ts & vagotonic individuals & $* 10.4(3.1 ; 16.6)^{*}$ & $* 3.7(-0.3 ; 8.8)^{*}$ & *15.8 (0.8; 29.0) & $15.2(7.0 ; 33.0)$ \\
\hline \multirow{2}{*}{ Td-Ts } & sympathotonic individuals & $1.1(-3.5 ; 4.9)$ & $-0.01(-6.0 ; 6.7)$ & $-0.9(-4.5 ; 3.8)$ & $1.6(-4.5 ; 5.9)$ \\
\hline & vagotonic individuals & $1.5(-3.6 ; 5.7)$ & $3.2(-1.6 ; 7.9)$ & $-2.3(-3.8 ; 6.1)$ & $0.3(-3.1 ; 3.8)$ \\
\hline
\end{tabular}

* on the left - stands for statistically significant differences between seasonal values within one group; ${ }^{*}$ on the right - specifies statistically significant differences between different groups within the same season.

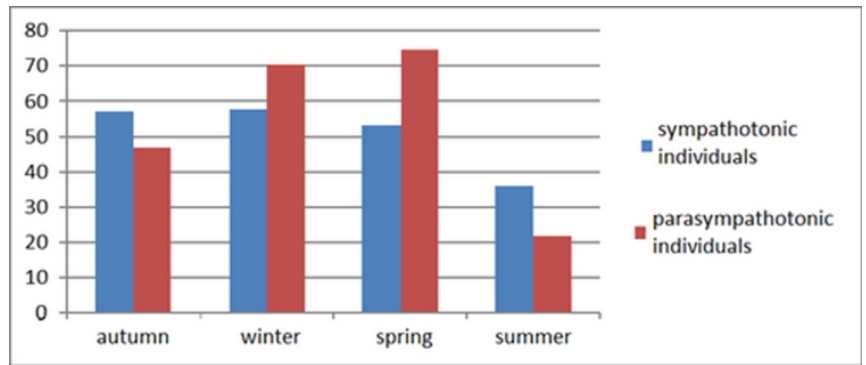

Figure 1. Seasonal dynamics of total DCPL values for monopolar leads in Arctic residents with different autonomic tones.

When analyzing the results of local indicators of individual brain lobe activity relative to the average energy consumption of the cortex, it was possible to trace a single trend in adaptive rearrangements of cerebral energy exchange processes in both study groups. Likewise, in both vagotonic and sympathotonic individuals, the local $\mathrm{Fz}-\mathrm{X}$ values of the frontal lobe were positive in the spring-and-summer period and negative in the fall-andwinter period. The local $\mathrm{Cz}-\mathrm{X}$ indicator of the central lobe was in the normal value range throughout the year. In contrast, the corresponding indicator of the left temporal lobe was negative during all four seasons. The local indicator of the right temporal region was positive solely in winter and negative in other seasons. Differences in local indicator values were recorded only in the occipital lead. Thus, in sympathotonic individuals, this indicator was negative in the fall-and-winter period, while in the vagotonic individuals, Oz-X signal had a value below zero only in winter. In other seasons, DCPL value in the occipital reading point was above average for the cortex.

The highest value of the total DCPL for monopolar leads in vagotonic individuals was recorded in winter and spring (Figure 1). In sympathotonic individuals, the highest cerebral energy expenditure was characterized by a period of decrease in the intensity of natural light, reaching the maximum at the onset of the 'biological polar night'. With the 'biological polar day', regardless of the autonomic tone type, Arctic region residents exhibited a sharp drop in the intensity of energy exchange processes in their cerebral cortex.

One of the indicators of normal DCPL distribution in the brain was following the bell-shaped curve [11], when there was a gradual decrease in the values of the potential from the central regions to the periphery (Figure 2).

According to Figure 2, the bell-shaped principle in sympathotonic individuals was observed for DCP values recorded in the fall and winter. In vagotonic individuals, it was in fall, winter, and spring, which indicated the normalization of energy exchange processes in the brain of the Arctic region residents over these seasons.

One of the critical parameters for assessing cerebral energy exchange processes is the analysis of interhemispheric energy asymmetry. It is usually evaluated by the results of the intertemporal difference (Td-Ts) [16]. In the group of vagotonic subjects, the intertemporal gradient had a positive value in the fall-and-winter period. In spring, with an increase in the intensity of natural light, the dominant hemisphere changes, as indicated by the negative value of this parameter. In summer, in this study group, the intertemporal difference was close to zero, which meant an absence of a clear dominance of any hemisphere. In sympathotonic individuals, we observed right hemispheric dominance of cerebral energy exchange processes in fall and summer, as evidenced by positive Td-Ts values. In winter and spring, the interhemispheric asymmetry gradient values were levelled off ( $\mathrm{Td}-\mathrm{Ts}<1 \mathrm{mV})$.

Our analysis of interelectrode differences also indicated a shift in the energy balance to the frontal lobe, accompanied by an increase in the intensity of natural light (Table 2). In fall and winter, in both groups, the maximum values were recorded for the interelectrode gradients $\mathrm{Cz}-\mathrm{Oz}, \mathrm{Cz}-\mathrm{Ts}$ and $\mathrm{Cz}-\mathrm{Td}$. In the group of sympathotonic subjects, the interelectrode differences associated with the frontal lead (Fz) had two negative values in fall and winter, one in spring, and all positive values in summer. This finding indicated the activation of the frontal cortex with increasing daylight hours. In the group of vagotonic individuals, the 
interelectrode differences associated with the frontal lead $(F z)$ in fall, winter, and spring had two or three negative values; and only in summer, all values were positive.

At minimum values of natural light, the activity of occipital cortex was diminishing, whereas at maximum values, it was augmenting due to the sensory information effect on the visual cortex of the brain, as evidenced by a decline in the interelectrode gradient, $\mathrm{Cz}-\mathrm{Oz}$, and an increase in the differences, Oz-Td and $\mathrm{Oz}-$ $\mathrm{Ts}$, in both groups.

\section{Discussion}

Analysis of the monopolar DCP values indicates the restructuring of energy exchange with the change in natural light intensity in individuals with different initial autonomic tones. According to the results of our study, the most balanced cerebral energy exchange in the Arctic residents, regardless of the type of an autonomic tone, is observed in the fall. DCP values were very close to the norm. In both study groups, a stable dominance of the energy activity in the right hemisphere was recorded. Analysis of the total DCPL suggests a higher activity of cerebral energy exchange in sympathotonic individuals, compared with vagotonic subjects, with a decrease in the natural light intensity. In turn, vagotonic individuals exhibit an intensification of energy exchange processes in their occipital lobe.

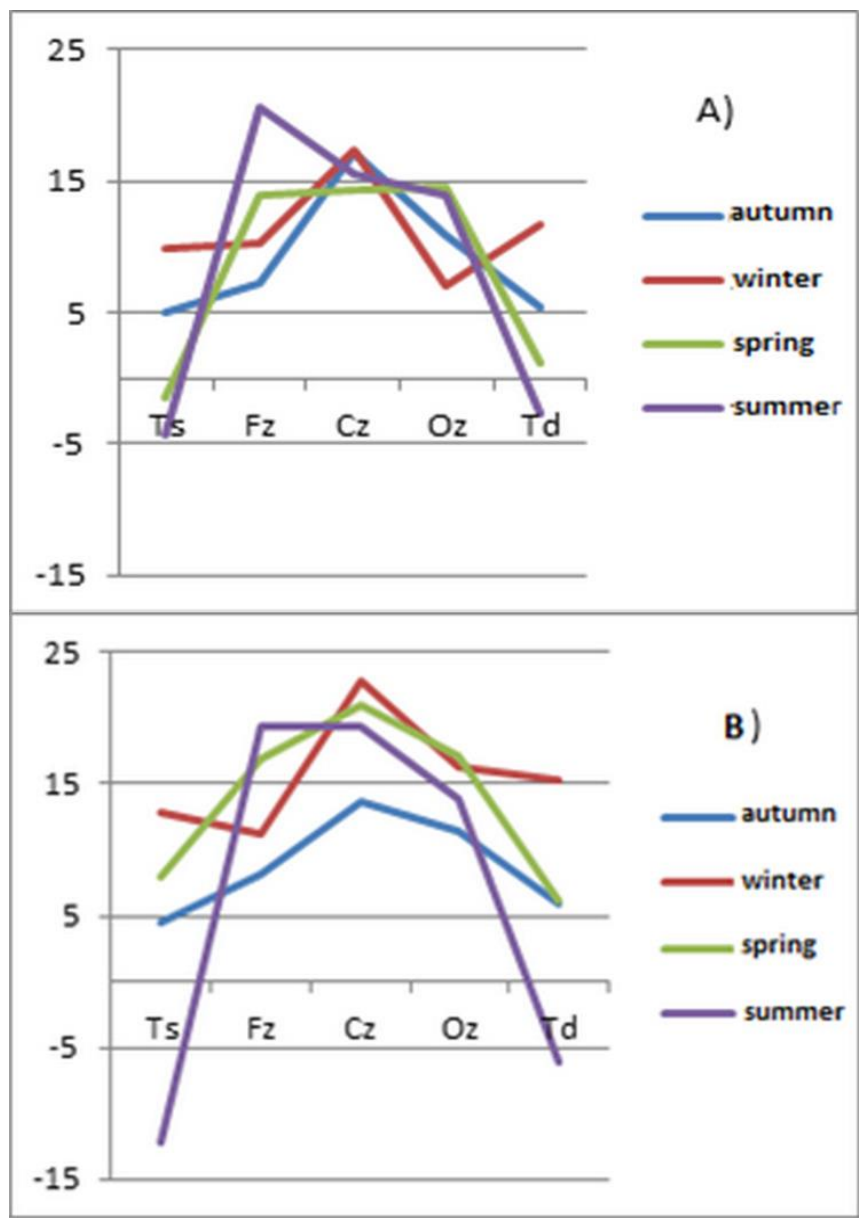

Figure 2. Annual dynamics of DCPL distribution profiles in monopolar leads of Arctic residents with predominance of sympathetic (A) or parasympathetic (B) initial tone.
The winter period in high latitude residents is characterized by a high level of cerebral metabolic processes. The most pronounced increase in total energy consumption is observed in people with a predominance of sympathetic activity of the autonomic nervous system, with a simultaneous decrease in the activity of their occipital lobe. A feature of the central nervous system in northerners during the so-called 'biological polar night' is represented by high activity of temporal lobes of their cerebral cortex. In comparison with the rest of the seasons, the DCPL index in these leads in both study groups have the highest values. There is a stable dominance of the right hemisphere in vagotonic individuals vs. the formation of a tendency to change the dominant hemisphere in sympathotonic subjects. The Td-Ts values in people with sympathicotonia are under $1 \mathrm{mV}$, indicating a close interhemispheric interaction, which, in turn, may imply an increase in interhemispheric connections, an inclusion of the cortex of both hemispheres in adaptive rearrangements of functional systems in the body. Besides, in this study group, there is a sharp drop in energy consumption of the occipital lobe.

With an increase in the intensity of natural light in the spring, the Arctic region residents exhibit a reduction in energy consumption in their central lobe, with an increase in the activity of the frontal and occipital lobes. In this case, there is a drop in values for the temporal lobes and a change in the dominant hemisphere. Sympathotonic individuals maintain close interhemispheric interaction $(\mathrm{Td}-\mathrm{Ts}<1 \mathrm{mV})$, while vagotonic individuals develop a stable dominance of their left hemisphere. In northerners with a predominance of their sympathetic nervous system, DCP values in three leads, located along the sagittal line, are almost equalized, forming a slight tendency to increase energy exchange along the gradient from the frontal lead to the occipital lead, thereby violating the bell curve principle of DCPL distribution. In vagotonic individuals, the potential level in their central lead remains at a maximum value, thus maintaining the normalization of redistributing energy exchange processes in their cerebral cortex.

Compliance with the principle of the bell-shaped DCPL distribution indicates the effective restructuring of energy costs in the cerebral cortex. At maximum values of natural light in summer, sharp deterioration in cerebral energy exchange was observed in both study groups. The most significant activity of energy processes was recorded in the frontal lobe, accompanied by the formation of an exhaustion area in temporal lobes. In both sympathotonic and vagotonic individuals, the bell-shaped curve principle was violated in terms of DCPL distribution. The total indicators for energy activity of the cerebral cortex reach the lowest values, compared with other seasons. A decrease in the intensity of cerebral energy exchange indicates the activation of subcortical systems; an imbalance occurs in the functioning of the brain structures. Therefore, daylight duration during this period in the Arctic region, in our opinion, should be considered a negative environmental factor affecting the cerebral energy exchange.

Hence, in people with parasympathetic tone predominance, normalization of the energy exchange processes in the brain is observed virtually continually throughout the year, except for the summer period; whereas in sympathotonic individuals, the indicators of cerebral energy exchange comply with the norm only during two seasons of the year. Adaptive responses to a change in the natural light intensity occur with an increase in activation influences on the frontal cortex of the cerebral hemispheres. Maintaining this condition is impossible without sufficient energy 
supply to neurons. When the sympathetic division of the autonomic nervous system is activated, the rate of oxidative processes increases, which leads to the DCPL increase in the cerebral cortex. Accordingly, an increase of the energy metabolism in the brain, with activation of the sympathetic nervous system and the frontal lobes of the cortex, constitutes the basis for the response program of the long-term adaptation to the Arctic conditions. However, this is accompanied by the stricter adaptive mechanisms and control functions.

\section{Conclusion}

Active stimulation of the sensory centers, along with intensive adaptation processes of visual sensory system to continually changing natural light conditions, lead to redistribution of the cerebral blood flow. The results of our study, conducted on the Arctic residents of the Russian Federation, indicate the presence of a close relationship between the seasonal natural light intensity on one hand, and the state of energy exchange processes in the brain and autonomic tone type on the other hand. There is an increase in cerebral energy metabolism in the frontal, central and occipital cortical lobes, along with its reduction in the temporal lobe.

Neurophysiological adaptative processes of the energy supply in the brain of vagotonic individuals are less pronounced during the annual cycle, whereas in the group of sympathotonic individuals, there is a pressure of adaptive processes.

\section{Conflict of interest}

The authors declare no conflicts of interest.

\section{References}

1. Wright KP Jr, McHill AW, Birks BR, Griffin BR, Rusterholz T, Chinoy ED. Entrainment of the human circadian clock to the natural light-dark cycle. Curr Biol 2013; 23(16): 1554-1558. https://doi.org/10.1016/j.cub.2013.06.039.

2. Bedrosian TA, Nelson RJ. Timing of light exposure affects mood and brain circuits. Transl Psychiatry 2017; 7(1): e1017. https://doi.org/10.1038/tp.2016.262.

3. Meyer C, Muto V, Jaspar M, Kussé C, Lambot E, Chellappa SL, et al. Seasonality in human cognitive brain responses. Proc Natl Acad Sci U S A 2016; 113(11): 3066-3071. https://doi.org/10.1073/pnas.1518129113.

4. Yoo HJ, Thayer JF, Greening S, Lee TH, Ponzio A, Min J, et al. Brain structural concomitants of resting state heart rate variability in the young and old: Evidence from two independent samples. Brain Struct Funct 2018; 223(2): 727-737. https://doi.org/10.1007/s00429-0171519-7.

5. Kumral D, Schaare HL, Beyer F, Reinelt J, Uhlig M, Liem F, et al. The age-dependent relationship between resting heart rate variability and functional brain connectivity. Neuroimage 2019; 185: 521-533. https://doi.org/10.1016/j.neuroimage.2018.10.027.

6. Winkelmann T, Thayer JF, Pohlack S, Nees F, Grimm O, Flor H. Structural brain correlates of heart rate variability in a healthy young adult population. Brain Struct Funct 2017; 222(2): 1061-1068. http://doi.org/10.1007/s00429-016-1185-1.

7. Aghajanian NA, Konovalova GM, Ozheva RSh, UrakovaTYu. The effect of external factors on the formation of adaptive reactions in human body. New Technologies 2010; (2): 142-144. Russian. https://www.elibrary.ru/item.asp?id=15173732.

8. Gribanov AV, Dzhos YuS, Bagretsova TV, Biryukov IS. Photoperiodism and changes in brain bioelectric activity in school students of the Arctic zone. Hum Physiol 2016; 42: 128-136. Russian. https://doi.org/10.1134/S0362119716020067.

9. Hasnulin VI, Hasnulin PV. Modern concepts of the mechanisms forming northern stress in humans in high latitudes. Human Ecology 2012; (1): 3-11. Russian. https://www.elibrary.ru/item.asp?id=17474846.

10. Botoeva NK, Urumova LT. The seasonal changes of heart rate variability in the students living in the foothills of the North Ossetia. RUDN Journal of Medicine 2012; (S7): 53-54. Russian. https://www.elibrary.ru/item.asp?id=20289935.

11. Fokin VF, Ponomareva NV. Energetic Physiology of the Brain. Moscow: Antidor. 2003; 288p. Russian.

12. Speckmann EJ, Elger CE, Gorji A. Neurophysiological Basis of EEG and DC Potential. In: Schomer DL, da Silva FL, Eds, Niedermeyer's Electroencephalography: Basic Principles, Clinical Applications, and Related Fields. Philadelphia: Lippincott Williams \& Wilkins. 2011: 1731. content/uploads/2012/12/ARTICLE.pdf. http://www.nrsign.com/wp-

13. Kottsova ON, Anikina Yu, Gribanov AV. Interhemispheric asymmetry and cerebral energy metabolismin young people living in the arctic zone of the russian federationduring the seasons with disturbed photoperiods. Journal of Medical and Biological Research 2020; 8(1): 23-32. Russian. https://doi.org/10.17238/issn2542-1298.2020.8.1.23.

14. Gribanov AV, Anikina NYu, Gudkov AB. Cerebral energy exchange as a marker of adaptive human reactions in natural climatic conditions of the arctic zone of the Russian Federation. Human Ecology 2018; (8): 32-40. Russian. https://www.elibrary.ru/item.asp?id=35377595.

15. Baevsky RM, Ivanov GG, Gavrilushkin AP, Dovgalevsky PYa, Kukushkin YuA, Mironova TF, et al. Analysis of heart rate variability when using different electrocardiographic systems (Part 1). Journal of Arrhythmology 2002; (24): 65-86. Russian. https://www.elibrary.ru/item.asp?id=9166688.

16. Fokin VF, Ponomareva NV, Krotenkova MV, Konovalova RN, Tanashian MM, Lagoda OV. Factors determining dynamic properties of functial interhemispheric Asymmetry. Asymmetry 2011; 5(1): 4-20. Russian. https://www.elibrary.ru/item.asp?id=16377314.

\section{Authors:}

Anatoly V. Gribanov - Honored Scientist of the Russian Federation, MD, Professor, Department of Human Biology and Biotechnical Systems, Northern (Arctic) Federal University, Arkhangelsk, Russia. https://orcid.org/0000-0002-4714-6408.

Olga N. Kottsova - PhD student, Department of Human Biology and Biotechnical Systems, Northern (Arctic) Federal University, Arkhangelsk, Russia. https://orcid.org/0000-0002-7004-6368.

Natalia Yu. Anikina - PhD, Lecturer, Department of Medical and Biological Physics, Northern State Medical University, Arkhangelsk, Russia. https://orcid.org/0000-0002-8115-0291.

Mikhail N. Pankov - Researcher, Central Research Laboratory; Associate Professor, Department of Hygiene and Medical Ecology, Northern State Medical University Arkhangelsk, Russia. http://orcid.org/0000-0003-32935751.

Larisa F. Startseva - PhD, Associate Professor, State Institute of Medicines and Good Practices, Moscow, Russia. https://orcid.org/0000-0002-9928$\underline{5362}$. 